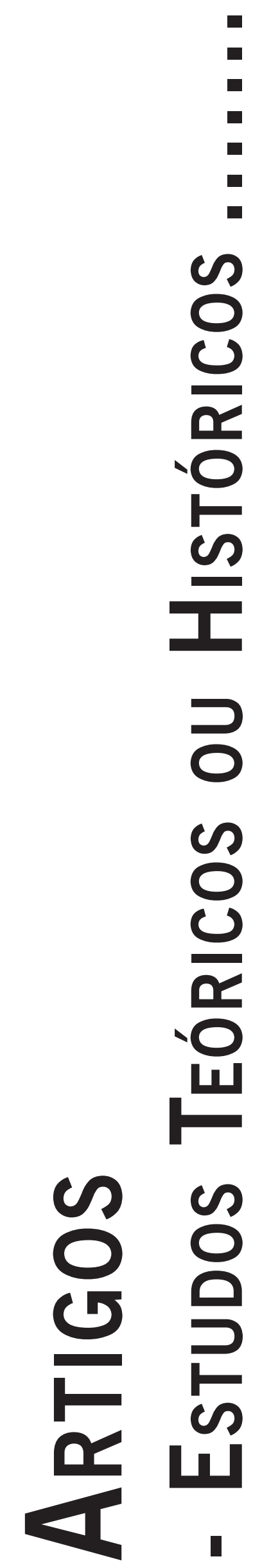




\title{
CONTRIBUIÇÕES DE VIKTOR FRANKL AO MOVIMENTO DA SAÚDE COLETIVA
}

\author{
Viktor Frankl's Contributions for the Colective Health Movement
}

Contribuciones de Viktor Frankl al Movimiento de la Salud Colectiva

DANIEL ROCHA SILVEIRA

FERNANDA JAUDE GRADim

\begin{abstract}
Resumo: Estudo teórico, em que se apresenta a Logoterapia de Viktor Frankl, enfatizando sua concepção sobre a busca e a descoberta/ encontro com o sentido da vida, bem como o vazio existencial, e suas decorrências. Apresenta-se brevemente o movimento da Saúde Coletiva. Propõe-se reflexão sobre contribuições de Viktor Frankl para a Saúde coletiva: é possível um diálogo profícuo entre Saúde Coletiva e Logoterapia.
\end{abstract}

Palavras-chave: Viktor Frankl; Logoterapia; Sentido da vida; Vazio existencial; Saúde coletiva; Diálogo.

\begin{abstract}
Theoretical study presenting Viktor Frankl's Logotherapy, emphasizing its conception about the search and discovery/ meeting of a meaning to life, as well as the existential emptiness and its consequences. The Collective Health Movement is briefly presented. There is a proposal of a reflection about Viktor Frankl's contributions for the Collective Health: it is possible a fruitful dialogue between Collective Health and Logotherapy.
\end{abstract}

Keywords: Viktor Frankl; Logotherapy; Meaning of life; Existential emptiness; Collective health; Dialogue.

Resumen: Estudio teórico donde se presenta la Logoterapia de Viktor Frankl, enfatizando su concepción acerca de la busqueda y descubrimiento/encuentro com el sentido de la vida, así como el vacío existencial y sus derivaciones. Brevemente se presenta el movimiento de La Salud Colectiva. Se propone una reflexión acerca de las contribuciones de Viktor Frankl para La Salud Colectiva: Es posible un dialogo fructífero entre La Salud Colectiva y Logoterapia.

Palabras clave: Viktor Frankl; Logoterapia; Sentido de la vida; Vacío existencial; Salud colectiva; Diálogo.

“O que esperamos nós quando estamos desesperados, e mesmo assim procuramos alguém? Esperamos, certamente, uma presença por meio da qual nos é dito que o sentido ainda existe”

(Martin Buber)

\section{Introdução}

Para o sociólogo Giddens (2002, p. 19), o mundo atual, por ele qualificado como alta modernidade, traz uma série de perigos: decorrendo que as chamadas crises são quase sempre presentes. Veja-se a economia no mundo atual e no Brasil - os desafios urgem e obrigam a uma busca de construção de superação - necessidade de tecer resiliência. A ONU afirma que a resiliência humana diz respeito às estratégias utilizadas para remover as barreiras que limitam as pessoas em sua liberdade de agir, sublinhando a importância de promover autonomia e de identificar e abordar as vulnerabilidades, bem como melhorar a sua capacidade para lidar com impactos. Para tanto, faz-se necessária uma ação coletiva, sob a forma de um compromisso global para o universalismo (UNDP, 2014, p. 8). Neste caminho, o pesquisador Ungar (2011) aponta uma visão comunitária da resiliência, construída e contextualizada nas culturas locais: a resiliência como a capacidade dos indivíduos navegarem e negociarem para alcançar recursos de saúde, bem como as condições do indivíduo, da família, da comunidade e da cultura para fornecerem tais recursos e experimentá-los de maneira significativa.

Ao navegarem e cuidarem de si e do outro, chegam inevitavelmente ao tema da saúde saúde coletiva. A saúde coletiva, de acordo com Carvalho (citado por Campos, 2000, p. 221), "nasceu da crítica ao positivismo e... à saúde pública tradicional, constituída à imagem e semelhança da tecno-ciência e do modelo biomédico". Valorizou a subjetividade que "brota da necessidade coletiva e que se organiza em sujeitos coletivos - no Estado, no partido, nas organizações classistas e comunitárias...” (p. 222). Vinculou-se ao paradigma da promoção à saúde (p. 222).

Mas o que é saúde e ser/estar saudável? As significações que são dadas, bem como as atitudes e comportamentos assumidos diante do que se pensa ser a saúde e a doença, são gestadas no entorno cultural (Uchôa \& Vidal, 1994, p. 503) - compreendendo cultura como uma teia de significações que pragmaticamente mapeia e cria 
o mundo, na qual se situam e orientam as pessoas - um conjunto de mecanismos de controle que norteiam o comportamento dos indivíduos (Geertz, 2008).

No trabalho na área de saúde, o profissional torna-se um cuidador, e aqui Minayo (2008) enfatiza que a relação entre o pesquisador em saúde e o participante da pesquisa deve ser permeada pela ética - a intersubjetividade e a solidariedade social são inseparáveis. Assim e aqui, a antropologia médica provoca para a construção de um novo humanismo, uma revalorização da pessoa, do usuário de serviços de saúde (Bibeau, 2010), distanciando-se de uma até possível certa assepsia biomédica - que, se por um lado permite uma desinfecção dos agentes biológicos patógenos, por outro desqualifica a experiência do paciente, criando uma barreira territorial entre duas subjetividades, marcada por sinais comportamentais que muram mundos diferentes: um universo do padecente e um possível olimpo protegido de um suposto detentor do poder-saber, que se coloca em um sistema social à parte, um condomínio (Dunker, 2015) reservado a uma autoconstruída quase casta. É fundamental o cuidado de fato, pois as condições humanas têm sua biologia - mas têm história, política, economia: e espelham diferenças culturais e subjetivas (Kleinman, 1998). Cuidar da saúde implica em cuidar de si e do outro - ação solidária coletiva. Adequada para uma prática ética, a antropologia da saúde abre-se para uma antropologia do humano, sensível ao que ele mostra de mais frágil, mas também de mais nobre, a solidariedade na luta contra o sofrimento e as desigualdades (Massé, 2010), e levanta a voz ao afirmar que cuidar é estar ao lado (Kleinman, 2009) - um ato de moralidade e respeito (Kleinman, 2012).

Sobreviver, até mesmo alcançando bem-estar e felicidade em meio a crises, é uma arte. Arte que em muito significa adquirir a capacidade de suportar sofrimento. (Kleinman, 2014). Sofrer faz parte de ser humano. Em sua humanidade, a pessoa pode de alguma forma "situar-se sempre ‘acima' de qualquer situação”, fazendo a experiência de uma "liberdade de algo" e "liberdade para" (Moreira \& Holanda, 2010, p. 354). Poder posicionar-se diante da situação dolorosa, distanciando-se dela para se fortalecer, respirar, escolher um caminho e prosseguir. Trabalhar em Saúde Coletiva implica em contribuir nesse processo: cuidar, cuidado e promoção de saúde.

Sobre "suportar", viveu e afirmou com propriedade o psiquiatra e neurologista Viktor Frankl - fomentador de resiliência (Silveira, 2007; Silveira \& Mahfoud, 2008) - a partir de sua própria experiência de sofrimento extremo como prisioneiro de campos de extermínio nazistas. Ali, comprovou sua cosmovisão prévia de que ter um sentido para a vida é o que mais fortalece, no sentido de suportar e superar as adversidades. Pode-se privar a pessoa de tudo, menos da liberdade última de assumir uma atitude alternativa frente às condições dadas (Frankl, 2008, p. 66-67).

Esta pesquisa teórica parte do pensamento-vida do psiquiatra Viktor Frankl e seu estudo sobre a questão do sen- tido, que é a característica essencial da vida humana para o autor, que implica na responsabilização do homem perante seus posicionamentos. Propõe-se tecer apontamentos sobre a busca pelo sentido da vida como fio condutor da existência saudável e então sobre as contribuições que o legado de Frankl traz à construção da saúde coletiva.

\section{A pessoa e o sentido da vida}

A pessoa pode ser considerada uma unidade múltipla - composta pelas dimensões biológica, psicológica, e também noológica/espiritual. O noológico/espiritual diz respeito ao fato de o ser humano ser livre e aberto à busca de um sentido para vida, ao posicionar-se diante de cada aspecto de seu ser biológico e seu ser psicológico. A mulher e o homem são determinados por características genéticas, congênitas, nutricionais, reativas biologicamente ao ambiente, são determinados por um passado histórico, uma história pessoal/familiar, uma dimensão psicológica. Mas estas determinações são o solo sobre o qual há um espaço para decidir o que se tornar, e abrir-se para a busca de um sentido. E aqui se está no ambiente da dimensão noológica/espiritual (ressalta-se que espiritual não se liga necessariamente a aspectos religiosos, mas sim ao que há de mais alto no ser humano, na possibilidade de ir além de si mesmo - autotranscendência - e distanciar-se das determinações bio-psíquico-sociais - autodistanciamento - caminhando para o sentido). Na existência saudável, a pessoa volta-se para (autotranscendência) um trabalho (obra, onde imprime criativamente sua marca própria), para uma pessoa (ou pessoas) a quem quer bem, ou até para uma busca de Deus, que pode incluir uma religiosidade (Frankl, 1989, 1993, 1997, 2008).

A essência da existência humana, diria eu, radica na sua autotranscendência. Ser homem significa dirigir-se e ordenar-se a algo ou alguém: entregar-se o homem a uma obra a que se dedica, a um homem quem ama, ou a Deus, a quem serve. Esta autotranscendência quebra os quadros de todas as imagens do homem que, no sentido de algum monadologismo (...), representem o homem como um ser que não atinge o sentido e os valores, para além de si mesmo, orientando-se assim, para o mundo, interessando-se exclusivamente por si mesmo, como se lhe importasse a conservação ou o reestabelecimento da homeostase (Frankl, 1989, p. 45)

Portanto Frankl (2005) propõe uma visão de homem que engloba três dimensões: somática, psíquica e noológica. A dimensão somática envolve aspectos corporais como as funções fisiológicas. Na dimensão psíquica, contemplamos os aspectos psicológicos como as sensações, sentimentos, instintos, desejos, afetos, cognições e emoções. A dimensão noológica ou espiritual engloba o que é essencialmente humano, os fenômenos humanos. É nes- 
ta dimensão que se encontram as decisões que tomamos, a criação estética, religiosidade, apreensão de valores, o sentimento ético. Além disto, Frankl não deixa de considerar que o ser humano constitui-se imerso e influindo no jogo de forças sociais (Frankl, 1989).

Frankl (1989) comprovou que o ser humano anseia por um sentido de vida, que a sua principal força motivadora é a busca deste sentido. Podem decorrer disso, como efeitos colaterais, a felicidade, o prazer e o encontro de um conforto no mundo social (sucesso profissional). A Logoterapia, criada por Frankl, traz o homem à consciência de seu ser-responsável enquanto fundamento essencial da existência humana. Responsabilidade significa responder às questões que a vida nos coloca a cada momento. Cada escolha que faço me remete ao que deixo de escolher, e estas escolhas descartam qualquer outra possibilidade, já que cada momento é único. "Cada momento encerra milhares de possibilidades, mas eu só posso escolher uma delas para realizá-la, condenando todas as outras ao não-ser" (Frankl, 1989, p. 66).

A temporalidade é algo importante para a questão do sentido. A filosofia existencial afirma que mesmo diante da transitoriedade é possível encontrar o sentido da vida. O passado seria a concretização do que já foi vivenciado - as experiências e os sentidos descobertos existem também como parte do passado, e por isso não são transitórios, são a pura realidade.

O presente é a fronteira entre a não-realidade do futuro e a realidade eterna do passado. Justamente por isso é a "linha demarcatória da eternidade"; em outras palavras, a eternidade é finita: estende-se só até o presente, o momento presente em que escolhemos o que desejamos admitir na eternidade. A fronteira da eternidade é onde, a cada momento de nossas vidas, é tomada a decisão sobre o que queremos eternizar ou não" (Frankl, 2005, p. 101).

Estamos inseridos em um espaço histórico concreto, que se organiza e tem valores que pautam o modo de vida. Frankl (1990) acredita que a sociedade cria necessidades para o homem e satisfaz algumas delas. Porém, há uma necessidade que fica pendente, a necessidade de sentido do homem, sua "vontade de sentido". A questão do sentido coloca-se em todas as etapas da vida. Exemplificando, a chamada "crise da meia idade" pode ser compreendida como uma crise de sentido, assim como a crise da aposentadoria e a crise de desemprego. Na crise de desemprego ou de aposentadoria, a pessoa entende que sem trabalho a vida não tem sentido, as pessoas não se sentem necessárias, úteis para si ou para a sociedade.

A vontade de sentido para Frankl (1990) é a motivação humana primária, mas não aparece somente quando as necessidades básicas do homem são satisfeitas, surgindo assim uma necessidade de satisfação mais elevada. A vontade de sentido representa uma motivação que não se reduz ou deriva de outras necessidades. Esta ideia contrapõe-se à de Maslow (Fadiman \& Frager, 1986) que propôs uma hierarquia das necessidades, sendo elas: fisiológicas, de segurança, de amor e pertinência, de estima e por último a auto-realização. Para este mesmo autor, as necessidades fisiológicas são básicas e devem ser atendidas primeiramente para que as demais ocorram. Para Frankl, o importante seria compreender qual das necessidades tem sentido para a pessoa, e não identificar sua hierarquia. "Se não existir algum sentido para seu viver, uma pessoa tende a tirar-se a vida e está pronta para fazê-lo mesmo que todas as suas necessidades sob qualquer aspecto estejam satisfeitas" (Frankl, 2005, p. 14).

Frankl (1989, p. 61) traz também o conceito de suprasentido, que seria "o sentido do mundo como um todo na forma de um conceito-limite”. O sentido da fé, por exemplo, não é um conceito limitador, mas sim criador e torna o homem mais forte. Diante de situações dolorosas incompreensíveis racionalmente - diante da impossibilidade de se responder à pergunta por que aconteceu isto comigo? - adere à crença de que há um sentido incondicional para a vida, e então há um sentido para o acontecido adverso. Pode ser apreendido pela fé.

A Psicanálise entende que o sentido decorre da busca de prazer. Para Frankl (1989, p. 67) “...esta afirmação reporta-se ao suposto fato de que todo o agir humano é fitado, em última análise, por uma aspiração à felicidade, sendo todos os processos anímicos determinados única e exclusivamente por um princípio do prazer”. Frankl não compartilha desta ideia: "o princípio do prazer é um artefato psicológico”.. Para Frankl: (1989, p. 67) "Na verdade, o prazer não é em geral a meta de nossas aspirações, mas sim a consequência da sua realização". Ou ainda: "Em outras palavras, o homem, que tão especialmente dedica-se ao prazer e diversão, mostra-se finalmente como alguém que permanece frustrado em relação a sua vontade de sentido". Somente quando a vontade de sentido se vê frustrada, o ser humano parte para a busca direta de prazer (Frankl, 1990).

Entre os estudiosos que abordaram a questão do sentido e sua importância na vida das pessoas, Jung (citado por Frankl, 1990, p. 26) afirmou que "o sentido faz muito, talvez tudo suportável”. Nietzsche acreditava que: "Quem tem por que viver, suporta quase qualquer como". Na percepção do sentido, trata-se de descobrir uma possibilidade diante do pano de fundo da realidade - trata-se da possibilidade de descobrir a melhor (mais adequada) alternativa diante das opções que a vida apresenta em determinado contexto - trata-se da possibilidade de se transformar a realidade (Frankl, 1989, 1990, 2005, 2008).

O sentido é algo subjetivo, na medida em que não há um sentido único para todos, mas sim um sentido para cada um: "a pessoa tem que atingir e captar o sentido, percebê-lo e efetivá-lo, isto é, realizá-lo”. Além disso, o sentido está em constante relação com a situação, por isso é único e irrepetível. Para captar este sentido nas ex- 
periências vividas, utilizamos a consciência, que é a capacidade intuitiva rastreadora do sentido que, por sua vez, é irrepetível e único e se esconde em cada situação (Frankl, 1989, p. 76).

Porque decerto só há uma resposta para cada pergunta, isto é, a resposta exata; para cada problema há apenas uma solução, a solução válida; e, em cada vida, em cada condição de vida, só um sentido, o verdadeiro... Contudo, na vida não se trata de uma atribuição de sentido, senão um achado de sentido; o que se faz não é dar um sentido, mas encontrá-lo; encontrar, dizemos, e não inventar, já que o sentido da vida não pode ser inventado, antes tem que ser descoberto (Frankl, 1989, p. 77).

A possibilidade de encontrar um sentido é única e original, apesar das mudanças sociais que possam ocorrer. Ao contrário dos valores construídos socialmente, o sentido, sendo único, não é afetado pela perda de valores da nossa época. Para Frankl, (1990) até mesmo quando somos acometidos pelo destino com alguma doença ou limitação, ainda é possível encontrar um sentido: "Com base nessa possibilidade de transfigurar o sofrimento pessoal em uma realização humana, a vida é potencialmente plena de sentido até o fim” (Frankl, 1990, p. 48).

Encontra o homem um sentido, então ele é feliz - por um lado; pois, por outro lado, ele é então capaz de sofrer. Se necessário, ele é então também capaz de fato, de ser abnegado, sim, de colocar sua vida em jogo. Ao contrário, porém, quando ele não conhece nenhum sentido na vida, ele zomba da vida, ainda que externamente possa parecer ir bem, e então sob certas circunstâncias ele põe tudo a perder (Frankl, 1990, p. 26).

\section{0 vazio existencial e a neurose noogênica}

A sensação de falta de sentido e de vazio, denominada por Frankl de "vácuo existencial”, aparece nos consultórios frequentemente. Para Frankl (1989, p. 26) "há pacientes que se dirigem ao psiquiatra porque duvidam do sentido da vida ou porque já se desesperaram até de encontrar, em geral, um sentido para a vida”.

Frankl (1990) acredita que a sensação de falta de sentido, em primeiro lugar, deve ser atribuída à perda de instinto, depois à perda da segurança na tradição. O ser humano não tem uma programação genética que lhe indique todos os seus passos na trajetória da vida. $\mathrm{E}$ as pessoas tornam-se cada vez mais alheias às questões da tradição, intensificando assim a sensação de falta de sentido. Não se sabe para onde ir, ou para onde se está caminhando. Mesmo em um suposto entorno social onde há ou haverá abundância material, o sentido é e sempre será basilar. "Quanto à origem do sentimento de falta de sentido, pode-se dizer, ainda que de maneira muito simplificadora, que as pessoas têm o suficiente com o que viver, mas não têm nada por que viver; têm os meios, mas não têm o sentido" (Frankl, 2000, p. 90).

Mas, ao homem que foi expulso do paraíso, onde havia abrigo e segurança proporcionados pelos instintos, e especialmente ao homem de hoje, que além dessa perda de instintos ficou entregue a si mesmo depois da perda da tradição, não é indicado pelos instintos o que ele tem de fazer nem pelas tradições o que ele deve fazer: a sua busca de sentido ainda lhe diz que ele quer dever. Mas ele frequentemente não sabe de mais nada que deva querer; em outras palavras, ele já não sabe nada do sentido em si (Frankl, 1991a, p. 69).

Não se compreende a falta de sentido como algo patológico, mas como algo próprio da humanidade da pessoa. "Nós sabemos que "sofrer de vida sem sentido" é um sofrimento, mas não uma doença. É, porém, a vida realmente sem sentido? E se tivesse sentido: seria possível comunicá-lo? Podemos nós dar sentido?” (Frankl, 1990, p. 39). Para Frankl, sofrer com a falta de sentido não significa, de forma alguma, estar doente, mas sim uma "expressão de maturidade espiritual”. O posicionamento pessoal diante do sentimento de vazio pode sim causar uma reação patológica, mas não se resume a isso, sendo também uma forma de expressão do ser humano. "Só ao homem é dado ter a vivência da sua existência como algo problemático; só ele é capaz de experimentar a problematicidade do ser" (Frankl, 1989, p. 56).

Quando a vontade de busca de sentido é frustrada, pode se formar um neuroticismo específico, que Frankl denominou de neurose noogênica, cuja sintomatologia chega a incluir alcoolismo, drogadição, violência, depressão e até suicídio. Portanto, a neurose noogênica surge a partir da dimensão noológica/espiritual do homem. Por exemplo, o uso de drogas seria consequência do sentimento de falta de sentido, que resulta de uma frustração das nossas necessidades existenciais. O suicídio surge como uma pseudo-solução diante do vazio existencial e o impulso de tirar a vida pode ser superado se a pessoa for consciente de um sentido que inclua propósitos pelos quais valha a pena viver - apesar de tudo (Frankl, 1993, 1997, 2000).

O homem não sabe o que fazer com seu tempo de lazer, ou com o tempo da aposentadoria, o que pode dar espaço ao vazio existencial. Este, por sua vez, pode ser terreno fértil para aflorar, por exemplo, o alcoolismo, onde a busca frustrada pelo sentido dá lugar à busca pelo prazer ou também a “doença do executivo", onde este vazio é substituído pela busca do poder (Frankl, 1991a). O tratamento significa contribuir para que o neurótico encontre sentidos para a sua vida, e consequentemente se motive também para se cuidar e engajar-se, dizendo um sim à vida, apesar das adversidades que enfrenta. O terapeuta ajuda 
a pessoa a perceber que há sentido para a vida, e facilita que se descubra este sentido. A descoberta é da pessoa, e não do terapeuta (Frankl, 1993, 1997, 2000).

O modo de vida das sociedades globalizadas atuais também pode ser entendido como uma forma de expressão do vazio existencial vivenciado, gerando angústia e depressão. As chamadas neuroses coletivas, segundo Frankl (1997), têm quatro sintomas: atitude provisória, postura fatalista diante da vida, pensamento coletivista e fanatismo. A atitude provisória seria a falta de decisão por parte da pessoa, assumir uma postura fatalista significa acreditar que é impossível lutar contra o que a vida lhe apresenta, apresentando-se em atitude passiva. Quando a pessoa se volta para o pensamento coletivista, não assume sua individualidade -torna-se uniforme com a massa. Já o fanático aceita apenas sua própria opinião, ignorando que o outro possa pensar diferentemente. Aferra-se a um conjunto de crenças rígidas - constantemente reforçadas e reafirmadas em pensamentos repetitivos (quase como mantras), que impedem um contato real e cuidadoso, empático, com o ser humano que se apresenta diante de si - gerando um formalismo normativo que aborta a espontaneidade e o gesto criativo. De acordo com Frankl (1997, p. 198): “Os quatro sintomas da neurose coletiva podem se reduzir a uma fuga da responsabilidade e um medo à liberdade".

\section{Descobrir ou criar o sentido?}

A cada dia, apresentam-se situações novas, imponderáveis, e reeditam-se situações previsíveis dentro da rotina de uma pessoa. Seja no âmbito laboral, seja no familiar, no de uma rede de amigos ou colegas - no ambiente próximo, medial ou distante - ao passar do tempo, situações escorrem. E permanecem perguntas, que se fazem no interior de cada um, no fundo, emergindo em momentos de silêncio, intervalos entre uma atividade e outra: há sentido para tudo isto? O que faço aqui? Há horizontes? Caminho para o nada? Ao final, como serei lembrado, se é que o serei? O que terei realizado, se é que há possibilidade de realizações? O que são realizações?

Segundo vários filósofos existenciais, citados por Yalom (1984), o homem precisa de um sentido para viver, que envolva metas, valores e ideais. Sem isso, ele pode chegar a uma atitude extrema, o suicídio. Porém, a única certeza que temos é de que não há nada absoluto e que tudo o que vivemos poderia ter sido de outra maneira. Portanto, Yalom (1984, p. 505), para quem o ser humano precisa criar um sentido para sua vida, levanta a seguinte questão: "Como pode um ser que necessita de um significado encontrá-lo em um mundo que não o tem”? A busca pelo sentido diz respeito à busca pela coerência. Quando nos perguntamos qual o sentido da vida, estamos nos referindo ao "sentido cósmico", da vida em geral; diferentemente da busca pelo sentido da vida em particular, que o mesmo chama de "significado terrenal", que se refere ao que é singular ao sujeito. Este significado cósmico permite ao homem ver diversas maneiras de significado na sua própria vida. O homem se sente mais reconfortado por acreditar que há um ser superior a ele, que possui um plano particular com relação a este ser. Com esta crença é possível estabelecer um modo de viver e de agir no mundo. Tirando o significado metafísico, o homem busca achar outro significado para sua existência. Trata-se sempre de criar - a partir dos elementos que a vida traz, das possibilidades de leitura da existência que a cultura disponibiliza - criar uma visão particular que responda à pergunta sobre qual é o sentido da vida.

Frankl (1989, 2005), por sua vez, tem sua visão própria, que desenvolveu já desde suas primeiras indagações na infância, e foi amadurecendo ao longo de sua travessia: o sentido da vida precisa ser descoberto, e não criado pela pessoa, diante das circunstâncias que a vida lhe apresenta, por mais trágicas que sejam. Por isso, o homem pode se posicionar e dar respostas às perguntas que a vida possa fazer. Cada momento traz uma pergunta, que representa um desafio e uma exigência - a vida desafia a pessoa a responder. "Responder a" é responsabilizar-se, comprometer-se perante uma tarefa que se apresenta, perante uma ou mais pessoas, perante Deus.

As respostas são dadas a partir de três possibilidades de caminho, chamadas de três categorias de valores: "criativos", "vivenciais" e "de atitude”. Os valores criativos se referem a uma tarefa, um trabalho, uma obra, onde se oferece algo ao mundo. Os valores vivenciais dizem respeito às experiências em que se recebe amor (de amigos, parentes, uma parceria amorosa, de Deus), recebe-se a beleza da natureza ou das manifestações artísticas, culturais. Já os valores de atitude são as respostas dadas perante as dores que a vida apresenta, e que não podem ser modificadas - são dizer sim à vida, mesmo diante dos sofrimentos que são inevitáveis (Frankl, 1989, 2005).

Os valores criativos podem ser vividos quando se cria em um trabalho. A profissão escolhida faz com que a pessoa tenha a possibilidade de realizar-se na atividade exercida, a partir do momento em que coloca ali sua unicidade. Não se trata de qual atividade de trabalho, mas que nesta atividade - que seja ética - a pessoa coloque, através de sua personalidade e seu modo de existir, sua contribuição. Na ação, de acordo com o que faz e da forma como faz, imprimir, em seu trabalho, seu estilo único (Frankl, 1989).

Os valores vivenciais acontecem quando experimentamos algo ou encontramos alguém. São valores que se realizam na experiência vital, onde um simples momento pode dar sentido a uma vida toda. "Com efeito, embora se trate de um só momento, pela grandeza de um momento já se pode medir a grandeza de uma vida”. Esta forma de encontrar um sentido na vida se dá através das relações com as pessoas, com a cultura e com a arte, e através da natureza (Frankl, 1989, p. 82). O sentido do amor 
é a única maneira de captar o outro no íntimo da sua personalidade.

Ninguém consegue ter consciência plena da essência última de outro ser humano sem amá-lo. Por seu amor a pessoa se torna capaz de ver os traços característicos e as feições essenciais do seu amado; mas ainda, ela vê o que está potencialmente contido nele, aquilo que ainda não está, mas deveria ser realizado (Frankl, 1989, p. 136).

Os valores de atitude se referem ao modo do homem se comportar perante as situações que geram sofrimento e que não podem ser mudadas. Para o mesmo (1989, p. 83) é sempre verificada a possibilidade de realização desses valores de atitude, "portanto, quando um homem arrosta um destino perante o qual nada mais pode fazer que aceitá-lo, suportá-lo; tudo está no modo como o suporta, tudo depende de que o carregue sobre si como uma cruz. Enquanto se depara com este valor de atitude, o homem é responsável e por isso, sua realização sempre continua possível”. Frankl enfatiza a importância do homem se posicionar de forma positiva, para encontrar um sentido nas dificuldades e descreve a tríade trágica que seria o sofrimento, a culpa e a morte. "Mesmo se a pessoa não puder mudar a situação que causa seu sofrimento, pode escolher sua atitude”. Se não for possível mudar a situação, é possível mudar a si mesmo (Frankl, 1989, p. 170).

Só quando o homem já não tem nenhuma possibilidade de realizar valores criadores; só quando ele já não está realmente em condições de configurar seu destino, só então pode realizar os valores de atitude; só nessa altura tem algum sentido, "carregar a sua cruz". A essência de um valor de atitude reside precisamente no modo como um homem se submete ao irremediável (Frankl, 2000, p. 155).

O sofrimento convida à descoberta de valores de atitude, e encontrando um sentido naquela situação dramática o homem faz a experiência de realizar sua humanidade. O autor entende que: "o sentido da vida é um sentido incondicional, por incluir até o sentido potencial do sofrimento inevitável”. É a oportunidade de transformar o sofrimento em uma conquista (Frankl, 1989, p. 138).

Em vista da possibilidade de encontrar sentido no sofrimento, o significado da vida passa a ser algo incondicional - ao menos potencialmente. (...) Assim como a vida permanece potencialmente significativa sob quaisquer circunstâncias, mesmo as mais miseráveis, também o valor de cada pessoa, sem exceção, a acompanha e o faz porque está baseado nos valores que a pessoa já realizou no passado (Frankl, 1989, p. 173).

A culpa pode gerar uma oportunidade de mudança de si mesmo para melhor. Se a culpa não for trabalhada de forma correta, pode impedir o crescimento da pessoa pelo fato de fixar-se em uma etapa da vida. Além disso, os sentimentos de culpa estão ligados à liberdade, responsabilidade e valores morais. Para Frankl (2000): "Entre as coisas que parecem tirar o sentido da vida humana estão não apenas o sofrimento, mas também a morte" (p. 144). Todavia, a transitoriedade da existência não tira o sentido da vida; mas sim constitui a responsabilidade de cada um, já que tudo depende da conscientização das possibilidades transitórias. A postura de enfrentamento da vida ajuda a pessoa a viver a vida de forma mais ativa e consciente.

Frankl, por apostar na renovação contínua dos valores através da atualização de novos sentidos únicos, opõe-se às tendências sociais de controle da nossa cultura, que nega a questão dos valores e da autonomia da consciência individual.

Esta degradação [dos valores], porém, vem a ser para o homem o preço pago por declinar de si os conflitos. (...) O caráter de conflito é antes inerente aos valores: na verdade, ao contrário do sentido das situações irrepetíveis e únicas de cada caso, que é concreto, os valores são, por definição, abstratos universais-desentido; como tais, não valem pura e simplesmente para pessoas inconfundíveis, inseridas em situações irrepetíveis, estendendo-se a sua validade a uma área ampla de situações repetíveis, típicas, que interferem umas nas outras (Frankl, 2000, p. 80).

Estas três categorias de valores (de criação, de vivência e de atitude) são as trilhas para se encontrar o sentido da vida. Esta, devido à sua dinamicidade, a cada hora nos possibilita vivenciarmos um tipo de valor.

\section{Encontro com o sentido no mundo da vida}

A ideia de uma busca direta da felicidade, que alimenta inclusive a indústria publicitária - como um argumento forte para a venda de produtos - essa ideia conduz a um círculo vicioso a partir da frustração de uma exigência (inerente à pessoa) profunda de busca de sentido. Quando o homem se limita à busca de auto-realização, está focado em si mesmo e no seu mundo, esquecendo-se do mundo que existe fora dele. O objetivo do homem é realizar um sentido, e somente quando ele o alcança consegue realizar a si próprio. A auto-realização vem como consequência, efeito colateral, da busca direta de sentido (Frankl, 1991a).

Ocorre que o homem que sempre se volta para si mesmo e só está preocupado com os seus próprios estados - seja porque ele quer ter uma consciência tranquila ou porque quer ter prazer e sossego - a pessoa que está nesse sentido preocupada somente consigo própria, e com os estados da sua alma, esqueceu-se de que lá fora, no mundo, um sentido concreto e pessoal espera por ela, que lá fora uma tarefa aguarda para ser realizada por ela, e por mais ninguém. Porque o homem só pode realmente es- 
tar consigo mesmo quando está com as coisas do mundo, quando ele está no mundo, quando ele se sai vitorioso no mundo (Frankl, 1991a, p. 66).

Sair vitorioso se relaciona a viver a vida como uma missão - considerar a vida em seu caráter de missão (Frankl, 1989). De forma consciente, racional, sensata, atuar se propondo a contribuir de alguma forma para o bem-estar do outro, sem deixar de cuidar de si, respeitar a si mesmo: "no experimentum crucis dos prisioneiros de guerra ou de campos de concentração foi demonstrado que não existe nada no mundo que torne o homem capaz de sobreviver a todas essas "situações-limite" como a consciência de uma missão na vida” (Frankl, 1991a, p. 68).

\section{Contribuições de Viktor Frankl à saúde coletiva}

Campos (2000, p. 225) pergunta-se:

Qual seria o núcleo da saúde coletiva? O apoio aos sistemas de saúde, à elaboração de políticas e à construção de modelos; a produção de explicações para os processos saúde/enfermidade/intervenção; e, talvez seu traço mais específico, a promoção de práticas de promoção [da saúde] e prevenção de doenças. (...) todas as profissões de saúde, as nucleadas na clínica ou na reabilitação ou no cuidado, todas, em alguma medida, deveriam incorporar em sua formação e em sua prática elementos da saúde coletiva. (...) a missão da saúde coletiva seria a de influenciar a transformação de saberes e práticas de outros agentes, contribuindo para mudanças do modelo de atenção e da lógica com que funcionam os serviços de saúde em geral.

Viktor Frankl, em sua história, em sua clínica, e em sua produção teórica, sempre desenvolveu preocupação com a saúde da população. Já em Viena em seus tempos de estudante de medicina, concebeu e implementou centros de aconselhamentos para jovens que estavam em risco eminente de cometer suicídio ou de fugas de casa. Com o aproximar-se da II Guerra Mundial, como médico em hospital, esforçava-se para contribuir ao máximo com a manutenção da saúde dos pacientes, até mesmo chegando a modificar prontuários, atenuando diagnósticos que, mesmo se reais, no contexto da perseguição nazista aos judeus levariam pessoas à chamada eutanásia (compulsória). A mudança do diagnóstico garantia a permissão para que o paciente permanecesse vivo (Rodrigues, 1996; Xausa, 1998).

O grande número de jovens que se suicidavam em Viena se explicava, na análise de Frankl, pelo fato de não terem perspectivas de vida, sentirem-se perdidos em um sentimento de falta de sentido (situação que não difere tanto daquela de milhares de jovens brasileiros, que se lançam também no uso compulsivo de crack - comentário nosso). Os centros de aconselhamento, onde trabalha- ram vários profissionais de saúde que aderiram à causa - motivados por Frankl, atuavam a partir de uma escuta acolhedora dos jovens, e um diálogo no qual a busca era de contribuir para conscientizar sobre o fato de a vida ter sim um sentido, ajudar o jovem a identificar em sua vida perante que obra, trabalho, projeto e/ou pessoas poderia se responsabilizar, fazer a diferença, mostrar sua unicidade, realizar sua missão. Os jornais, após algum tempo, noticiavam que a frequência de suicídios baixou para zero (Rodrigues, 1996; Xausa, 1998).

Posteriormente, ao coordenar uma ala psiquiátrica de um hospital geral - ala destinada aos pacientes depressivos suicidas, Frankl seguiu a mesma lógica de contribuir para que o paciente encontrasse seu horizonte de valores, de sentido, a partir do qual valeria inclusive suportar o sofrimento do estado depressivo, para direcionar-se ao futuro, a um futuro digno, valoroso - na crença de um sentido incondicional para a vida, do poder escolher dizer um sim à vida, apesar de tudo (Rodrigues, 1996; Xausa, 1998).

O chamado grande experimento, experimentum crucis, porém - a vida de prisão nos quatro campos de extermínio nazistas - permitiu a Frankl o forçoso e compulsório laboratório, onde ele mesmo se reconheceu como participante de um processo dolorosíssimo, onde o maior fator com valor de sobrevivência foi a crença de que a vida tem sentido mesmo nas piores circunstâncias: a busca cotidiana, com grande esforço, de encontrar este sentido. (Frankl, 1989, 2008; Rodrigues, 1996; Xausa, 1998). Ali, fundamental foi conseguir suportar (Kleinman, 2014), e isso, a partir da certeza no sentido, motivou a construção de um processo de resiliência (Silveira, 2007; Silveira \& Mahfoud, 2008).

Em toda a sua travessia vital, vislumbramos atitudes que se inserem perfeitamente na visão que se construiu sobre saúde coletiva (Campos, 2000). Em uma grande coerência entre vida pessoal privada, linha de pesquisa, práxis clínica, escrita e docência, Frankl mostrou sua dignidade: houve um grande cuidado (Kleinman, 1998, 2009, 2012, 2014) com a pessoa (inclusive o assim-designado paciente), em um trabalho inclusive em rádios e televisão, na direção da promoção da saúde (Frankl, 1991b). Frankl afirmou que o sentido de sua vida estava em contribuir para que as pessoas encontrassem os sentidos de suas vidas.

Campos (2000, p. 228) sugere que "os sanitaristas e demais profissionais de saúde assumam explicitamente uma visão de mundo fundada na radical defesa da vida das pessoas com as quais trabalhem”. A saúde coletiva constrói-se no movimento sanitarista, na constituição e defesa do SUS (Sistema Único de Saúde), no processo de promoção da dialética do ser saudável. Esta construção é um vir-a-ser (como se refere Sartre), uma busca constante (Minayo citado por Campos, 2000, p. 227), com uma renúncia à pretensão de constituir verdades (conforme Foucault), em abertura para dar voz aos trabalhadores de saúde, acadêmicos, usuários, gestores: “caberia aos trabalhadores e aos usuários, a partir de seus próprios desejos 
e interesses, apoiando-se em uma teoria sobre a produção de saúde, tratar de construir projetos e de levá-los à prática” (Campos, 2000, p. 228).

Pontilhar as conversas e diálogos, considerando a tradição democrática do movimento da Saúde Coletiva (Campos, 2000) - em que se cuidam/gestam/nascem práticas e reflexões. Pontilhar encontros com temas propostos por Viktor Frankl, como autotranscendência/autodistanciamento, vontade de sentido, valores de criação/vivenciais/ atitudinais, supra-sentido, vazio existencial, neuroses coletivas e noogênicas, podem trazer consistentes nutrientes e saborosos frutos.

\section{Considerações finais}

A saúde coletiva chama a conceber os sujeitos que buscam tratamento por uma condição de saúde adversa como cidadãos - possuidores de capacidade de pensamento crítico. E a trabalhar para a promoção da saúde, a partir de um processo de empoderamento do sujeito como construtor de projetos de vida confortável e saudável, que incluem questões como sua empregabilidade, acesso à educação, acesso ao lazer, melhoria da mobilidade urbana, redução de fontes de stress, melhoria da convivência, participação em mobilizações políticas não partidárias e partidárias. Saúde que transcende em muito uma visão de ausência de doenças, chegando à confecção de autonomia e bem-estar, e projeto - agora com Frankl (1989, 1990, 1991a, 1991b, 1993, 1997, 2005, 2008), encontro de seu projeto de vida que se situa na trilha da descoberta do seu sentido único - que inclui pensar-se para "como missionado a ser si mesmo, realizando algo no mundo. A logoterapia, em sua missão de contribuir para a qualidade de vida humana, coloca-se disponível ao movimento da saúde coletiva.

Logoterapia "é uma terapia que ousa elevar-se à dimensão do espiritual” e logos significa "sentido”, aponta para dimensão noológica/espiritual. A logoterapia, especificamente, enfoca a atitude do paciente diante do sintoma.

(...) a logoterapia procura direcionar e orientar o paciente para um sentido concreto e pessoal. Ela não tem função de dar sentido à existência do paciente, afinal de contas, ninguém esperaria nem mesmo exigiria que a psicanálise, que se ocupa tanto da sexualidade, arranjasse casamentos ou que a psicologia individual, que se ocupa tanto da sociedade, arranjasse empregos; assim, tampouco a logoterapia arranja valores. Não se trata de darmos ao paciente um sentido da existência, mas apenas de o tornarmos capaz de descobrir o sentido da existência, de ampliarmos, por assim dizer, o seu campo de visão, de forma que ele perceba o espectro completo de possibilidades de sentido e de valores pessoais e concretos (Frankl, 1991a, p. 72).
Para que o paciente tenha consciência de um sentido possível, o psicoterapeuta deve estar consciente de todas as possibilidades de sentido, como o sentido do sofrimento, sob um destino inalterável ou até mesmo fatal: "este sofrimento, contém a possibilidade de realizar o sentido mais profundo e os valores mais elevados: assim a vida, até o último momento, não deixa de ter um sentido" (Frankl, 1991a, p. 72). A logoterapia torna o paciente consciente de que ele é responsável, deixando-o perceber e decidir por si mesmo - sendo responsável perante o que ou quem. Portanto, cabe ao homem perceber, entre as possibilidades que lhe são apresentadas, qual ou quais se destacam como as que são as melhores para serem realizadas.

Cada dia, cada hora proporciona um novo sentido, e um sentido especial espera cada pessoa. O sentido é, portanto, sempre um outro. Mas sempre há um, até o fim. Pois não há pessoa para a qual a vida não prepararia uma tarefa, e não há situação na qual a vida pararia de nos oferecer uma possibilidade de sentido (Frankl, 1981, p. 46).

Na verdade, não cabe ao homem indagar sobre o sentido de sua vida. Ele deveria (...) compreender-se como alguém que é indagado, e é justamente sua própria vida que o indaga, e ele tem de responder, ele tem de se responsabilizar pela sua vida. De fato, a análise existencial vê no ser responsável a essência da existência do homem (Frankl, 1976, p. 73).

A busca pelo sentido é uma necessidade humana, porém a nossa sociedade faz com que a cada dia tenhamos mais aflorada a sensação de falta de sentido. Diferentemente de outros autores, Frankl acredita que o sentido da vida não é algo que pode ser atribuído ou criado por nós, ele se coloca a cada dia como um desafio e exigência a ser descoberto. Encontrar este sentido que permeia e estrutura a vida, evita que a pessoa se desajuste e acabe adoecendo. O sentido da vida é essencial: a busca por sentido é o que move cada um.

A sociedade brasileira - com suas tensões e contradições, mas também com seus recursos e belezas - é cenário de habitação para tantos sujeitos, que, humanos, vivem sua dialética pessoal e coletiva de saúde e doença. O movimento da saúde coletiva, e então o SUS, inseremse neste processo com a função de contribuir para a promoção e construção de sujeitos saudáveis e autônomos, em projetos democráticos. (Campos, 2000).

Neste artigo pretendeu-se apresentar a Logoterapia de Viktor Frankl, e apontar para um diálogo com o movimento da Saúde Coletiva. O ser humano padecente apresenta-se. A vida convida a continuar o trabalho para a construção de resiliência - busca da felicidade possível em um mundo adverso: promoção de processo de construção de saúde. Fica o convite a aprofundar esta convivência. 


\section{Referências}

Bibeau, G. (2010). Quel humanisme pour notre âge bio-tchnologique? L'antropologie, horizon nécessaire de l'antropologie médicale. Anthropologie \& Santé: Revue internationale francofone d'anthropologie de la santé, 1, s/p. URL: http:// anthropologiesante.revues.org/91; DOI: 10.4000/anthropologiesante.91

Campos, G. W. S. (2000). Saúde pública e saúde coletiva: campo e núcleo de saberes e práticas. Ciência e saúde coletiva, 5 (2), 219-230.

Dunker, C. I. L. (2015). Mal-estar, sofrimento e sintoma. São Paulo: Boitempo.

Fadiman, J. \& Frager, R. (1986). Teorias da personalidade. São Paulo: Harbra.

Frankl, V. E. (1989). Psicoterapia e sentido da vida: fundamentos da Logoterapia e análise existencial. São Paulo: Quadrante.

Frankl, V. E. (1990). A questão do sentido em psicoterapia. Campinas: Papirus.

Frankl, V. E. (1991a). A psicoterapia na prática. Campinas: Papirus.

Frankl, V. E. (1991b). Psicoterapia para todos: uma psicoterapia coletiva para contrapor-se à neurose coletiva. Petrópolis: Vozes.

Frankl, V. E. (1993). A presença ignorada de Deus. Petrópolis: Vozes.

Frankl, V. E. (1997). Teoría y Terapia de lãs neurosis: Iniciación a la logoterapia y al análisis existencial. Barcelona: Herder.

Frankl, V. E. (2005). Um sentido para a vida: psicoterapia e humanismo. São Paulo: Ideias e Letras.

Frankl, V. E. (2008). Em busca de sentido: um psicólogo no campo de concentração. Petrópolis: Vozes.

Giddens, A. (2002). Modernidade e identidade. Rio de Janeiro: Jorge Zahar Editor.

Geertz, C. (2008). A interpretação das culturas. Rio de Janeiro: L T C.

Kleinman, A. (1998). Experience and its moral modes: culture, human conditions, and disorder. Stanford University.

Kleinman, A. (2009). The art of medicine Caregiving: the odyssey of becoming more human. The Lancet, 373 (9660), 292-293.

Kleinman, A. (2012). Caregiving as a moral experience. The Lancet, 380 (9853), 1550-1551.

Kleinman, A. (2014). The art of medicine: how we endure. The Lancet, 383 (9912), 119-120.

Massé, R. (2010). Les nouveaux défis pour l'anthropologie de la santé, Anthropologie $\&$ Santé, 1, s/d. URL: http://anthropologiesante.revues.org/116; DOI: 10.4000/anthropologiesante.116.
Moreira, N. \& Holanda, A. (2010). Logoterapia e o sentido do sofrimento: convergências nas dimensões espiritual e religiosa. Psico-USF, 15 (3), 345-356.

Minayo, M. C. S. (2008). Anthropological contributions for thinking and acting in the health area and its ethical dilemas. Ciência e Saúde Coletiva (Rio de Janeiro), 13 (2), 329-339.

Rodrigues, L. A. (1996). Sobre o fundador da Logoterapia: Viktor Emil Frankl e sua contribuição para a Psicologia. Monografia Não Publicada, Universidade Federal de Minas Gerais, Belo Horizonte.

Silveira, D. R. (2007). O sentido da resiliência: a contribuição de Viktor Emil Frankl. Dissertação de Mestrado, Universidade Federal de Minas Gerais, Belo Horizonte.

Silveira, D. R. \& Mahfoud, M. (2008). Contribuições de Viktor Emil Frankl ao conceito de resiliência. Estudos de Psicologia (Campinas), 25 (4), 567-576.

Uchôa, E \& Vidal, J. M. (1994). Antropologia Médica: elementos conceituais e metodológicos para uma abordagem da saúde e da doença. Cadernos de Saúde Pública (Rio de Janeiro), 10 (4), 497-504.

Ungar, M. (2011). Community resilience for youth and families: Facilitative Physical and Social Capital in Contexts of Adversity. Chidren and Youth Services Review, 33, 1742-1748.

UNDP (2014). Human Development Report: Sustaining Progress: Reducing Vulnerabilities and Building Resilience, 2014. New York: United Nations Development Program.

Xausa, I. A. M. (1988). A psicologia do sentido da vida. Petrópolis: Vozes.

Yalom, I. (1984). Psicoterapia Existencial. Barcelona: Editorial Herder.

Daniel Rocha Silveira - Graduado em Psicologia e Mestre em Psicologia Social pela Universidade Federal de Minas Gerais, com Especialização em Psicoterapia de Abordagem Existencial-Fenomenológica e Gestáltica (FEAD) e Formação em Logoterapia (SOBRAL). Doutorando em Saúde Coletiva, Antropologia do Envelhecimento pela Fundação Oswaldo Cruz/Centro de Pesquisas René Rachou, Belo Horizonte, MG. E-mail: danielrochasilveira@gmail.com

Fernanda Jaude Gradim - Possui Graduação em Psicologia pelas Faculdades Integradas Pitágoras, com Especialização em Psicologia Clínica: Existencial e Gestáltica pela FEAD e Especialização em Saúde Mental: Política, Clínica e Práxis pela PUC Minas.E-mail:fejaude@yahoo.com.br

Recebido em 25.04.2014 Primeira Decisão Editorial em 10.09.2014 Segunda Decisão Editorial em 20.02.2015 Aceito em 28.10.2015 